whereas $19 \%$ of the women on diuretics had hypokalaemia of varying degrees.

My conclusions are that the evidence in favour of a general recommendation of potassium supplementation in elderly, nondigitalised cardiac patients on diuretics is insufficient and that elderly women are probably more prone to diuretic-associated hypokalaemia than elderly men.

R KRAKAUER

Old People's Town,
Copenhagen, Denmark

Wilkinson, P R, et al, Lancet, 1975, 1, 759 Edmonds, C J, and Jasani, B, Lancet, $1973,2,8$ ${ }^{3}$ Healy, J J, et al, British Medical fournal, 1970, 1, 716. Down, P F, et al, Lancet, 1972, 2, 721.

Davidson, C, et al, Lancet, 1976, 2, 1044.
Krakauer, R, and Lauritzen, M. To be published.

\section{Beta-blockers and lipid metabolism}

SIR,-Your leading article "Diet, energy balance, and genes-and serum cholesterol" (26 March, p 789) discusses the factors influencing lipid metabolism in relation to the genesis of ischaemic heart disease. The multifactorial basis of the common hyperlipidaemias is well demonstrated and you conclude by suggesting that further studies are needed to investigate the metabolic basis of the common hyperlipidaemias.

Adrenergic beta-blocking drugs have an established role in the treatment of ischaemic heart disease and hypertension and possibly exert a protective influence against myocardial infarction. These drugs have been shown to have many metabolic effects ${ }^{1}$ and in particular there is evidence that they are capable of reducing free fatty acid levels during stress. ${ }^{2}$ :3 However, little is known of the long-term effects of beta-blockade upon lipid metabolism. Recently Waal-Manning ${ }^{4}$ in a clinical study reported that the cardioselective drug metoprolol produced a significant rise in plasma triglyceride levels by as much as $42 \%$. This observation is worrying since increased plasma triglyceride concentration is a recognised risk factor in ischaemic heart disease. It is possible that the chronic administration of adrenergic beta-blocking drugs to hypertensives, especially those with a pre-existing hyperlipaemic tendency, may not be beneficial in this respect.

I would suggest that there is a need for studies to investigate the long-term effects of beta-blockade upon lipid metabolism.

S P DEACON

Pilgrim Hospital,

Boston, Lincs ' Himms-Hagen, J, Pharmacological Reviews, 1967, 19,

Bjorntorp, P, et al, Acta Pharmac
logica, 1967, 25, suppl 2, p 51 .

logica, 1967, 25, suppl 2, p 51.

omerville, W, et al, in New Perspectives in Beta-
blockade, ed D M Burley et al, p 275 . Horsham, Ciba Laboratories, 1973.

' Waal-Manning H J, Drugs, 1976, 11, suppl 1, p 121.

\section{The reprint game}

SIR,-In recent issues there have been a number of letters expressing the attitudes of authors towards reprints. For some time now I have been making it a practice to enclose one American dollar in currency with each request for a reprint. It seems to me that this might constitute a mutually satisfactory general practice. I figure that if my interest is not that great I shouldn't be asking anyone else to go to any trouble. For the author filling the request this will just about assure that his out-of-pocket expenses are met.

Midland, Michigan

A A Holzschum

\section{Emetic response to salt}

SIR,-I hasten to disagree with the suggestion of Drs C J C Roberts and H McNulty (26 March, p 840) that the sudden loss of consciousness of a 57-year-old woman following an overdose of oxprenolol (26 February, p 552) could have been caused by the salt emetic (which acted almost immediately) given by her husband. I wish to give an example of how the administration of a double-dose salt emetic which remained in a man's stomach for nearly an hour before being removed by another emetic did not have any dire consequences.

At 7 am in 1930 a young man, 21 years old, woke up with Monday morning depression and saw a green liniment bottle marked Poison on the mantle shelf. $\mathrm{He}$ decided to commit suicide, drank the contents, and threw the bottle out of the window, and stayed in bed to await results. At 7.45 am he felt ghastly, changed his mind, and called out to his brother to fetch the doctor at once. I came round by $8.15 \mathrm{am}$. He said that he did not know what the liniment was he had swallowed. He looked very pale and his lips were blue, but there was no corrosion around his lips or mouth.

I said, "I must go and find the bottle." $\mathrm{He}$ replied, "Don't leave me mate; save me!" I went through the first-aid book routine and gave him two tablespoons of salt in a tumbler of water with my compliments. He swallowed easily, but there was no emesis. After five minutes another two tablespoons of salt in a tumbler of water went down comfortably-still no result. I decided to go to the chemist's shop round the corner to fetch some apomorphine. He cried, "Don't leave me mate." I uttered the famous words from ITMA: "I go, I come back," and left. The chemist was raising his shutters at 9 am. I collected a tiny tube with 10 hypodermic tablets of apomorphine 1/20 grain ( $3 \mathrm{mg}$ ) each, and dissolved one tablet in a teaspoon of boiled water. I gave him a subcutaneous injection and three minutes later he brought up a bowlful of soapy looking water smelling of methyl salicylate linctus.

I went home to do the morning surgery and returned to the house to be told at 11 am that he had got out of bed, dressed and gone to work.

The emetic response to salt and water is usually under five minutes-as occurred in the oxprenolol case. In my case the salt and water remained for approximately an hour in this man's stomach. I believe that the methyl salicylate had an anaesthetic effect on the mucosa of the pharynx, oesophagus, and stomach preventing any sensation of nausea.

The man was quite well after this suicidal attempt.

The first-aid handbook, 1929, says: "Repeat salt and water emetic every five minutes until vomiting occurs." This could be quite considerable if it was kept up for an hour-24 tablespoons of salt and 6 pints of water before emesis. For salt intoxication it all depends on how much is swallowed, how long it stays down, and how much is absorbed.

Apomorphine injections (or oral tablets) are no longer available. This stopped about 10 years ago because they were being over-used in so-called aversion therapy for alcoholism. Today ipecac syrup is recommended for use in the home. It is not readily available in all households but salt certainly is.

Beta-blockers are now being widely prescribed for angina and hypotension. The oxprenolol fatality does show that anyone who swallows a month's supply in one go and seeks help when staggering is beyond the aid of emetics and pacemakers. Perhaps relays of attendants giving external cardiac massage for hours, without undue force, may be the solution.

N C HYPHER

Slough,

Berks

\section{Allergy to diazepam}

SIR,-My attention has been drawn to the letter of $\operatorname{Dr} S \mathrm{~K}$ Majumdar (12 February, $\mathrm{p} 444$ ), in which I am quoted as saying that the active and common metabolite of all benzodiazepines is desmethyldiazepam. In fact I state ${ }^{1}$ that desmethyldiazepam is the common metabolite of several benzodiazepines including medazepam, diazepam, and clorazepate. However, oxazepam is a metabolite of desmethyldiazepam and, like its chlorinated derivative, lorazepam, is fairly rapidly metabolised by conjugation with glucuronic acid and then excreted. Finally, both nitrazepam and flurazepam belong to different metabolic chains. Accordingly, cross-allergenicity between the various benzodiazepine groups cannot be automatically attributed to desmethyldiazepam.

MALCOLM LADER

Institute of Psychiatry,

University of London

' Lader, M, in Advanced Medicine-Topics in Therapeutics, 2, ed P Turner, p 212. London, Pitman

\section{Miscellaneous expense grants}

SIR,-Many hospital doctors eligible for removal expenses are, I believe, experiencing difficulties in claiming reimbursement of unavoidable expenditure on moving. The BMA is trying to negotiate equality for doctors who, unlike any other NHS staff, cannot claim this grant as a lump sum. I would be grateful if any doctors who have examples of their hardship could write to me to support our claim to the Department of Health.

B J BURKE

Royal Devon and Exete Senior medical registrar

Hospital (Wonford),

Barrack Road,

**The Secretary writes: "The HJSC nego tiating team is well aware of the problem. Negotiations have been going on for some time but have been thwarted by pay policy. The BMA secretariat has been and is in direct touch with the representatives of junior staff in the South-west Region. Some progress with the Health Departments is being made, but detailed figures would be most useful, particularly if copies of correspondence could be sent to the Secretary."-ED, BMF.

\section{Breath, alcohol, and the law}

Sir,- The article by Dr T A A Alobaidi and others (18 December, $p$ 1479) reported a wide range of values for the blood:breath partition coefficient for alcohol and concluded that "breath analysis is not an acceptable method for accurately determining blood alcohol concentrations." Referring to the claim that a 
coefficient of $1: 2370$ seems a reasonable guess, the authors commented that " 'a reasonable guess' should not be used to obtain a conviction in a court of law."

An answer to this was given at the 7th International Conference on Alcohol, Drugs, and Traffic Safety in Melbourne, Australia, 23-28 January 1977, with a resolution that breath alcohol concentration should be expressed as such for legislative purposes. In spite of individual variation there are levels at which drivers are relatively unsafe, and good epidemiological data collected in traffic can make a breath alcohol limit as legitimate as a speed limit. The classic conclusion of Borkenstein $e t a l^{1}$ in the Grand Rapids Study was originally stated in terms of blood alcohol concentration, but, when restated in the breath alcohol concentrations that they actually measured and given to the nearest whole number (in brackets to 3 digits), it reads as follows, "Breath alcohol concentrations over 4 micromoles per litre $(4 \cdot 14)$ are definitely associated with an increased accident rate. The probability of accident involvement increases rapidly at breath concentrations over $8: u \mathrm{~mol} / 1$ (8.28) and becomes extremely high at concentrations above $15(15 \cdot 5) . "$

The propriety of convicting someone in a court of law on a measurement that is subject to biological variation was considered recently by the Australian Law Reform Commission, which concluded in its report:" "We are talking here of averages not universal rules ... legislation in a field such as this cannot, and perhaps should not, seek to concern itself with the myriad of individual variations that are possible. However relevant such factors may be in the trial of an individual accused, legislation, while fixing a just balance between the interests of the accused and the interests of society, is entitled to look to averages . . . the proper approach must be to give greater weight to the social problem being tackled by the law. ..."

T C BEARD

Canberra,

Australia

' Borkenstein, R F, et al, The role of the drinking driver in traffic accidents (The Grand Rapids Study), 2nd edn, ed R F B

2 Australian Law Reform Commission, Report No 4, Alcohol, Drugs and Driving, para 285. Canberra,

\section{Coeliac disease and mental illness}

SIR,-Dr J P Crawford (26 March, p 841) points to the observation that in a sample population of 100000 only four patients presenting both coeliac disease and mental illness were discovered over a period of 17 years. Recently Dr Hudson and colleagues ${ }^{1}$ have found that wheat-gliadin components are cytotoxic to cultured human cells, including cells other than intestinal ones. This then implies that there are possibly many undiagnosed gluten-intolerant patients who would not be diagnosed as coeliacs on conventional tests such as jejunal biopsy. In this context Drs Sewell and Blenkinsopp" have reported transitory, self-provoked gluten intolerance in a previously fit young woman.

It follows that the role of gluten intolerance in relation to mental illness should not be dismissed, as implied by Dr Crawford. Indeed, evidence for a link between mental illness and gluten intolerance exists in a "blind" study by
Drs Singh and $\mathrm{Kay}^{3}$ and more indirectly in some recent books. ${ }^{45}$

F ABDULLAH

City University

London EC

Hudson, D A, et al, Lancet, 1976, 1, 339.

2 Sewe!l, J R, and Blenkinsopp, E C, Lancet, 1976, 1 , 638.

${ }^{3}$ Singh, $M$ M, and Kay, S R, Science, 1976, 191, 401.

Dickey, L. D (ed), Clinical Ecology. Springfield, Charles C Thomas, 1976.

Mackarness, R, Not All in the Mind. London, Pan,
1976.

These considerations have no relevance to one important part of the Health Service-the provision of asylums for the mentally disturbed and subnormal and the frail and senile old. Because of the increasing age of the population we are going to need far more asylum accommodation-in hospitals, old people's homes, or other institutions.

Frimley, Surrey

JOHN W TODD

\section{Sombre diagnosis: conservative}

treatment

SIR,-Your leading article (26 March, p 794) says: "as demands and resources can never be matched rationing in one form or another is inevitable." Time and again in medical journals we read about the "demands" of the public, no doubt egged on by politicians who in your words, lay "regular emphasis on the 'free' NHS.'

In fact, the public can only demand an interview with a GP or attention at a casualty or venereal disease department. Everything beyond this is underwritten by one of us. In 1974 we signed prescriptions costing $f 200 \mathrm{~m}$ The number of pathological investigations we ask for doubles every seven years, and the number of $x$-rays doubles every 12 years. In 1975 we signed forms for 211 million $x$-rays GPs refer some eight million patients to consultants each year. And there are some 30 million follow-up attendances at outpatien clinics. Many surgeons insist on keeping patients who have had, say, abortion or hernia repairs in hospital for days, whereas other surgeons do these operations without admission. And some operations, including most childhood tonsillectomies, most removals of the "chronic appendix," and some hysterectomies, are of questionable value. Many physicians admit walking patients for investigations which-even if these can be justified-could be done without admission They may also admit patients for certain kinds of treatment, including the initial treatment of diabetes, medical treatment of peptic ulcer, or starvation for obesity, which is either un necessary or in the long run worthless. Rheumatic patients in their thousands attend physiotherapy departments for various physical treatments, all prescribed by doctors, ye very little of it is of proved value. Unfortunate patients with inoperable cancer or widespread metastases are given radiotherapy and cance chemotherapy which makes them feel more il in the rarely fulfilled hope that their lives will be prolonged.

If only we doctors would prescribe far fewer drugs, much less physiotherapy, and request many fewer $x$-rays and pathological investigations; if only GPs would refer fewer cases to consultants; if only consultants would more quickly return outpatients to the care of their GPs and discharge inpatients sooner to their homes; if only surgeons would be more restrained in operating; if only physicians would cease to admit walking patients to acute medical wards; if only radiotherapists would just treat those patients likely to derive worthwhile benefit: most of our problems would be solved and the extra $£ 500 \mathrm{~m}$ which the BMA and the other health professions asked for in 1974 would not be needed. When we doctors waste resources on this vast scale it ill becomes us to blame the politicians, the bureaucrats, and the public for its "demands."

\section{Points from Letters}

\section{Any future for graduate medical} students?

Mr K Foord (Sheffield) writes: The new medical school at Southampton has not been the only medical school to adopt the policy of admitting a good percentage of mature and/or graduate students. Sheffield has had the policy for many years of admitting 10-12\% of such students annually. A fair number of other liberal-minded schools have been doing the same. The reason seems to be that such students act as a steadying influence, often do very well, and become excellent doctors as they are highly motivated. The present financial climate is dealing two direct blows to these students, who are often self- or spousesupported. Firstly, fees are being increased to an extortionate extent. Secondly, such students are often recipients of discretionary major grants from local education authorities, but the number of such awards is being cut back at an alarming rate as education authorities exercise this "discretion" as they are squeezed.

Unless one has a personal fortune, a very able spouse, or extremely generous parents able to provide at least $£ 7500$ over five years medicine is once again taboo for the graduate. This realisation, among other reasons, led to the active participation by medical students in sit-ins at Sheffield University to persuade the university to be a bit more active in fighting the fees increase. Such participation by medical students is uncommon, and was much supported in spirit as well as body. I can only sympathise with $\mathrm{Mr}$ A $\mathrm{M}$ Corrigan and others (26 March, p 841). His is not a local problem affecting a few students, but a national one affecting several hundreds. How many graduate students will find that they will not be able to afford to complete their courses? What a waste in both personal and national terms, with each student costing the nation $£ 5000$ or so a year! . .

\section{Anabolic steroids and gynaecomastia}

Dr A J BANks (Withington Hospital, W Didsbury, Manchester) writes: I have recently seen a third case of bilateral gynaecomastia in athletes who have engaged in the practice of using anabolic steroids to improve their performances.... I would be very interested to hear from any other readers who have had experiences of this nature.

\section{Verbal non medica}

Dr C D LACEY (Chichester) writes: I think Mr S Bender's English teacher may have been misleading his pupils (2 April, p 900). Was he not guilty of confusing a zeugma with a syllepsis (see Fowler's Modern English Usage)? 